


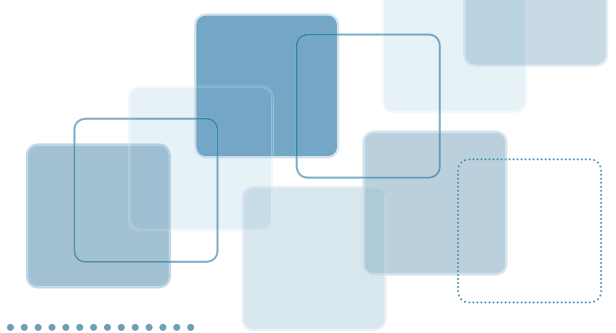

\section{NARRAR ES CONTAR LO QUE ACONTECE TODOS LOS DÍAS}

Después del almuerzo los frailes y los maestros tomaron el café, compartieron algunas anécdotas e hicieron comentarios frente al acervo epistemológico de lo cotidiano. Luego se reunieron en la Sala de Juntas, Carlos Ariel sacó su portátil, abrió el archivo Word donde tenía el trabajo de investigación y lo proyectó a través del vídeo beam en una de las paredes del recinto. - Lo cotidiano ha sido estudiado, como acabamos de ver, desde múltiples disciplinas y perspectivas metodológicas que brindan al estudio de este una mejor comprensión -dijo. Ahora, legitimar la validez de las inferencias en el proceso de investigación, garantizará que el proceso de razonamiento por el cual hemos optado, nos puede conducir a conclusiones ciertas. La indagación por la vida diaria, es un proceso que se desarrolla en un círculo continuo. En él participan las distintas voces disciplinarias, escuelas y autores que han hecho de lo cotidiano su interés teórico. Esta continuidad indefinida sugiere precisar un método y una serie de opciones metodológicas, asegurando que el conjunto de hechos y episodios investigados gocen de validez y de un alto grado de certezas científicas. 
-En La invención de lo cotidiano, Certeau hace de los hombres comunes, héroes anónimos -interpeló Luis Eduardo. Por consiguiente, el material-fuente para una investigación de este orden está en lo que Maffesoli ha denominado amb entes b réticos posmodernos. La espontánea aventura de tatuarse, colocarse piercing en áreas pudendas, vivir felizmente el acontecimiento del bar, la taberna, el after party, adentrarse en el recorrido de un código grosero y zafado que libera los gestos, las expresiones y las posturas corporales, apropiarse de los resquicios urbanos y de la vida nocturna, viajar por el ciberespacio, compartir con los otros internautas lo ilimitado del viaje a través de la red, vivir felizmente en las plazoletas de los centros comerciales el placer de estar juntos, disfrutar la música excitante y el baile erótico o la forma sugestiva y desinhibida de vestir, son entre otras, las fuentes polifónicas para tenerse en cuenta.

-Hemos decidido - con Luis Eduardo y Carlos Ariel- que el método de investigación biográfico-narrativa es el camino adecuado para nuestra investigación —dijo Rubén Darío. Este se interesa principalmente por las "voces" propias de los sujetos y del modo cómo estos expresan sus propias vivencias. Los relatos y narraciones de los sujetos pedagógicos son recursos culturales que, en gran medida, dan sentido a la vida escolar. Por tanto, investigar los relatos de los estudiantes, padres de familia y maestros contribuye a comprender, por ejemplo, cómo la escuela construye su identidad, qué sentido tiene para la vida de estos y qué papel juega en su educación.

- La investigación biográfico-narrativa no es solo una metodología cualitativa -agregó Carlos Ariel. Hoy se ha constituido en un enfoque legítimo para construir conocimiento en educación, haciendo del estudio de las narrativas del profesorado y sus estudiantes, una opción epistemológica recurrente para comprender lo que sucede en la escuela, así como también lo que pasa por fuera de ella. De esta forma, la investigación biográfico-narrativa se puede emplear de tres maneras, como fenómeno, método y uso. El fenómeno narrativo se interesa por el relato, escrito o hablado. Historias de vida, entrevistas biográficas, 
narraciones autobiográficas, documentos y fotografías personales, entre otros, son importantes instrumentos de reflexión oral y escrita, a través de los cuales se pueden identificar las experiencias personales de los actores educativos, de que manera organizan sus conocimientos y logran comprender la realidad. Bolívar y Domingo afirman que "la narrativa, como fenómeno, explora los modos como se concibe el presente y conceptualiza las dimensiones intuitivas, personales, sociales y políticas del quehacer educativo" (2001, p. 123).

Por su lado, el método representa la forma para construir, reconstruir y deconstruir los relatos personales, a través de la interpretación y análisis de los datos recolectados. El uso narrativo constituye los dispositivos usados para promover el cambio en la práctica docente, currículos, planes de estudios y estrategias de enseñanza. Las narraciones autobiográficas serán, en la presente investigación, tema de interés inusitado. En este ámbito, el fenómeno narrativo, el método narrativo y los usos narrativos serán las coordenadas básicas para desarrollar el trabajo investigativo. Las historias de vida, relatos narrativos, de los estudiantes, padres de familia, docentes y otras autoridades académicas serán interpretadas, analizadas, construidas, deconstruidas y reconstruidas a través de distintos momentos metodológicos, narrativos, con la intención de proponer cambios sustanciales en "las maneras de hacer" la escuela, usos narrativos.

-Entender la vida cotidiana desde el relato narrativo de sus actores, implica esclarecer el encadenamiento lógico de los razonamientos investigativos -interrumpió Luis Eduardo. Existen dos tipos de análisis en la investigación biográfico-narrativa, ambos son legítimos, válidos y fiables. El anĺ isis paradigmá ico de datos narrativos está basado en el estudio de historias de vida, relatos orales o escritos, entrevistas biográficas. Su interés se centra en proponer generalizaciones a partir de los casos estudiados. Por consiguiente, este tipo de análisis busca agrupar los datos y hechos recolectados en temas comunes derivando en una teoría, rodeada de categorías y conceptos, que el investigador ha logrado construir de la información analizada. El anḱ isis narrativo, 
propiamente dich también está basado en relatos orales, pero su interés no es general sino particular. Este tipo de análisis no busca temas comunes para configurar la historia.

La forma de presentar la información final, tanto de uno como de otro, nos conduce a tomar la primera forma de análisis como alternativa pertinente de cara al objetivo de la presente investigación. El anḱ isis paradigmá ico de datos narrativos sugiere que los resultados de la investigación se presenten en lenguaje académico, tipo de tesis de grado, mientras que El an $\not \mathbf{l}$ isis narrativo, propiamente dich propone un relato novelado. Nosotros presentaremos los resultados de este trabajo de acuerdo con este y no con aquel, es decir, un informe novelado, a la usanza de El mundo de $\delta f$ ía, de J. Gaarder -finalizó.

-Ahora bien, toda investigación tiene unos principios metodológicos —continuó Rubén Darío. La metodología y las estrategias biográficas: las historias de vida, los relatos autobiográficos y las entrevistas biográficas no hablan por sí mismas. Necesitan del diálogo fluido entre narrador e investigador, es decir, en el proceso de investigación narrativa nos interesa el discurso, relato, de los "otros", es decir, los estudiantes, además, importa las representaciones con las que estos construyen el mundo. Esta investigación la desarrollaremos en los siguientes momentos metodológicos - hizo una pausa prolongada y atendió la interpelación de Carlos Ariel.

- Mediación entre la historia individual y la h storia social —dijo Rubén Darío. Roland Barthes afirma que "el relato comienza con la misma humanidad" (p. 101). La socialidad consiste en la relación del individuo con los otros individuos, proceso que se hace contando e imaginado historias, es decir, narrativas. Las historias de vida no son siempre individuales, lo cual supone que además de conocer la propia vida del narrador, es decir, su personalidad, también se puede comprender el contexto social. Bolívar y Domingo han encontrado que lo social "se constituye en lo personal, la singularidad de una historia personal puede ser una vía de acceso al conocimiento social 
en el que está inmerso o ha vivido" (2001, p. 115). La mediación entre una y otra nos permitirá conocer las representaciones individuales de los estudiantes, como también la comprensión que estos tienen de la escuela y de la educación.

-Principio de saturación y relatos en paralelo -continuó Luis Eduardo- El interés de la perspectiva biográfico-narrativa, para esta investigación, es la generalización formal a partir de historias de vida singulares. El número de relatos será menor en las autoridades académicas con relación al número de los estudiantes. Se hará a través del principio de saturación, es decir, se recogerán tantas entrevistas biográficas e historias de vida (relatos autobiográficos) hasta cubrir todo lo que se quiere obtener. El conjunto de estos relatos será la base para la construcción conceptual de la teoría que se desea desarrollar. Además, el principio de relatos en paralelo será complementario del primero. En este se identificarán las estructuras polifónicas, es decir, las distintas voces presentes en el relato, se combinarán y alinearan entre sí, buscando temas comunes y los casos más dispares.

-Diferentes anḱ isis de contenido. Lo cotidiano es muy diverso. Las situaciones diarias, los escenarios y los sujetos dan cuenta de su dinamismo -interpeló Rubén Darío. Comprender los relatos narrativos por los que se manifiesta la vida cotidiana exige una triangulación para comprender todas las técnicas, entre las que se destacan: los distintos documentos, las inferencias frente a los aspectos significativos, las intencionalidades, énfasis y silencios de los narradores, las metáforas empleadas y los análisis realizados. Serán los investigadores y los coinvestigadores quienes realizarán este ejercicio conceptual.

- La verdad narrativa. La historia de vida o registro autobiográfico no se puede considerar como un registro de lo que sucedió, sino como una interpretación de las experiencias humanas - dijo Carlos Ariel. Es decir, no es del resorte de la narrativa definir qué es verdadero y qué no lo es. En este trabajo se apreciará lo expresado por cada uno de los narradores, con coherencia, verosimilitud, autenticidad y convicción. 
- Tema y personas. Lo cotidiano y todas las expresiones que suceden en la vida de los sujetos escolares, será el tema de la investigación —agregó Rubén Darío. Se analizarán el contexto en que estos se desenvuelven y sus experiencias de vida. Nos interesan sus voces. La manera de seleccionarlos depende de la disposición y la fluidez de sus relatos frente al tema de lo cotidiano.

— ¿...Y en qué momento entramos nosotros? — dijo Patricia.

—¿Cuál es nuestro trabajo en esta investigación? —interpeló Tulio.

—En el marco de las estrategias metodológicas, la selección y adiestramiento del equipo de coinvestigadores es muy importante dijo Luis Eduardo. Ustedes por el éxito que tienen con sus estudiantes, los padres de estos y sus colegas. Su trabajo consiste en seleccionar al azar, los estudiantes, padres y maestros que serán objeto de nuestro estudio. De ellos recogerán sus relatos, autorrelatos e historias de vida para identificar qué acontecimientos cotidianos engalanan la vida de nuestros actores educativos y qué escenarios sirven de núcleo para propiciar el saber escolar. En últimas, lo que intentamos resolver son los siguientes interrogantes: ¿Por qué la escuela debe considerar lo cotidiano? ¿Qué situaciones cotidianas pueden generar saber científico? ¿Cómo aprendí a ser maestro, padre, hijo, etc.? ¿Para qué sirve lo cotidiano en la escuela?

Además —enfatizó Luis Eduardo, el próximo 15 de febrero de 2013 se realizará un foro educativo con reconocidas autoridades académicas, dirigido a estudiantes, padres y maestros del "Santoto". Su objetivo es acercar a la comunidad al tema de lo cotidiano. Con esta información, los maestros, los estudiantes, los padres de familia, los investigadores y los coinvestigadores intentaremos dar una respuesta a la pregunta ¿Cómo puede, desde lo cotidiano, el colegio Santo Tomás de Aquino realizar su quehacer pedagógico? 
Ahora bien, nosotros como investigadores principales y ustedes como coinvestigadores, evaluaremos conjuntamente los resultados. Se trata de identificar los escenarios, acontecimientos y habilidades cotidianas de los sujetos educativos de nuestra comunidad. La interpretación de la información recolectada la realizaremos a través de los principios de saturación y relatos en paralelo.

—¿Cómo lo hacemos? —dijo Andrea.

-Pueden crear grupos en Facebook — dijo Luis Eduardo. En este, los sujetos (estudiantes, padres y maestros) publicarán sus relatos.

—QQué les preguntamos? -interpeló Lina, con dejo paisa.

—En el caso de los estudiantes les tendremos que preguntar ¿Qué hacen después de clases? ¿Qué hacen los fines de semana? ¿Qué sitios frecuentan? - dijo Luis Eduardo. A los padres de familia, a través de la técnica de las entrevistas, les preguntaremos que hacen con sus hijos, nuestros estudiantes, cuando ellos no están en el colegio. Finalmente, a los maestros, también a través de las entrevistas, les preguntaremos ¿De todo lo que viven los estudiantes en su vida cotidiana qué es susceptible de ser trabajado en el aula de clases para provocar el saber racional?

En últimas, es conocer el mundo de los otros, es decir, el mundo de los sujetos pedagógicos del colegio Santo Tomás de Aquino. 
